\title{
INHERITANCE IN NICOTIANA TABACUM
}

\section{$X X X$ : AUTOTRIPLOIDY, A POSSIBLE MEANS OF INCREASING THE RATE OF INTERSPECIFIC GENE TRANSFER}

\author{
ROM MOAV* \\ Deportment of Genetics, University of California, Berkeley
}

Received :8.xii.6I

\section{INTRODUCTION}

THE smaller the degree of effective homology between chromosome sets of two different species, the lower the frequency of interspecific chromosomal pairing and segmental exchange in their hybrids (Clausen, 1952). This low rate of exchange is a limiting factor restricting utilisation of interspecific gene transfer in experimental and commercial breeding of plants. A search for methods which would increase the rate of exchange has led (on theoretical grounds) to the hypothesis that autotriploidy of a recipient species should provide alien chromosomes with a better chance for pairing and exchange of segments with the recipient's chromosomes.

The present paper describes an attempt to test this hypothesis experimentally with hybrid derivatives of Nicotiana tabacum and $\mathcal{N}$. plumbaginifolia.

\section{MATERIALS AND METHODS}

The "White-Seedling" (Ws) locus of Nicotiana tabacum $(n=24)$ was chosen (Moav, 1957). Its recessive allele ws conditions an inability to induce chlorophyll production. The dominant gene of the species $\mathcal{N}$. plumbaginifolia $(n=10)$, which covers the effect of tabacum's ws has been designated Ws $(p b g)$.

When introduced by hybridisation into a tabacum nucleus, the plumbaginifolia chromosomes become somatically unstable, that is, they tend to be lost during somatic divisions. Thus hybrids carrying the recessive ws alleles in all their tabacum genomes are usually mottled (Ar-rushdi, 1957; Cameron and Moav, 1957; Moav, 1958; Moav, 1961). This character provides an easy and fairly reliable phenotypic distinction between hybrid derivatives which carry only ws alleles (mottled) and those possessing one or more Ws alleles (self green) in their tabacum genomes.

\section{EXPERIMENTAL PROCEDURES AND RESULTS}

The immediate purpose of the experiments was a comparison of the rate of transfer of the $W_{s}(p b g)$ locus to $\mathcal{N}$. tabacum chromosomes in autotriploid and diploid nuclei. The tests on the diploid level were carried out with mottled diploid heterozygous alien addition plants (2 sets of tabacum chromosomes plus a plumbaginifolia univalent carrying the $W s(p b g)$ locus: $2 n$ ws ws $(t b c)+$ I $W s(p b g)$. The equivalent autotriploid derivatives ( $3 n$ ws wos ws $(t b c)+\mathrm{I} W_{s}(p b g)$ ) were selected from

* Present address : Department of Botany, The Hebrew University, Jerusalem. 
progenies of crosses between simplex autotetraploid $t b c$ ( $4^{n} W s$ ws ws $w s(t b c)$ ) with the mottled diploid alien addition plants (2n wos wos $(t b c)$ $+1 W s(p b g))$. The desirable alien addition triploid offspring were mottled. They were progeny tested to determine the unpaired condition of the plumbaginifolia (henceforth abbreviated pbg) univalent (table I).

\section{TABLE I}

Transmission rates of the $\mathrm{Ws}(\mathrm{pbg})$ locus of the mottled autotriploid alien addition plants ( $3 \mathrm{n}$ tbc ws ws ws $+\mathrm{I} \mathrm{Ws}(\mathrm{pbg})$ ), when backcrossed to diploid homozygous recessive tabacum (2n tbc ws ws) *

\begin{tabular}{|c|c|c|}
\hline $\begin{array}{l}\text { Tested } \\
\text { autotriploid } \\
\text { plants }\end{array}$ & $\begin{array}{l}\text { Proportion of } \\
\text { non-albina } \\
\text { offspring } \dagger\end{array}$ & $\begin{array}{c}\text { Designation of } \\
\text { back-cross } \\
\text { populations }\end{array}$ \\
\hline $\begin{array}{l}\text { 55R91 } 22 \\
\text { 55 } 92 \mathrm{R}_{2} \\
55 \mathrm{R} \text { 100p } \\
56 \mathrm{R}_{1 \mathrm{p} 2}\end{array}$ & $\begin{array}{c}\text { Per cent. } \\
24 \cdot 8 \\
24 \cdot 2 \\
20 \cdot 5 \\
20 \cdot 3\end{array}$ & $\begin{array}{l}6{ }_{5} R_{55}, 56 R_{56}+ \\
56 R_{57} \\
56 R_{62} \\
56 R_{5}\end{array}$ \\
\hline
\end{tabular}

* Albino (chlorophyll-less) shoots that developed on mottled diploid alien addition plants served as homozygous recessive parents.

$\dagger$ The proportion of non-albino (self-green plus mottled) offspring is equal to the transmission rate of the $W s(p b g)$ locus. Over roo seedlings were tested in each case.

$\ddagger$ The two populations originated from two different capsules. Fig. 1.- The Breeding Procedure.

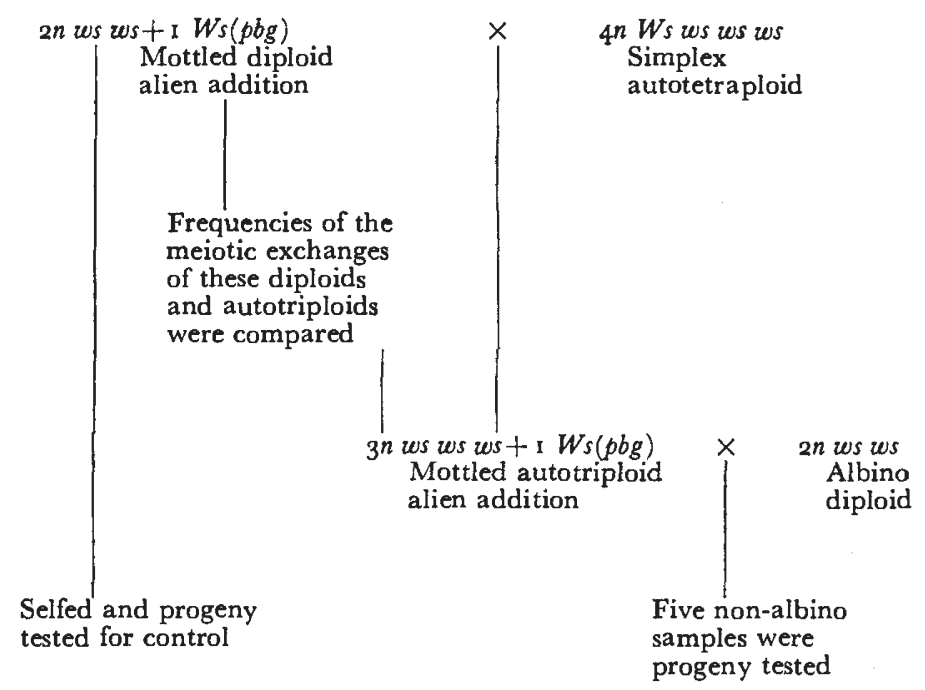

Four tested autotriploid alien addition plants were backcrossed to homozygous recessive diploid $\mathcal{N}$. tabacum (henceforth abbreviated $t b c$ ), and five samples of offspring each of 26 randomly selected nonalbino seedlings were grown and progeny tested (table I, right column). The breeding procedure is presented schematically in fig. I. 


\section{Plate}

Fig. 1.-Some ears obtained from self-pollination of $D e^{t^{1}} d e^{\mathrm{ta}} / d e^{\mathrm{t} 1} D e^{\mathrm{t} 2}$ plants. The majority of plants of this constitution give rise to ears showing about $5^{\circ}$ per cent. of defectives, together with a minority of ears segregating for only one of the two defective types, for both defectives in coupling phase and very rare cases of ears with no defective. The ratio of such four types of ears from the normal viable seeds of these ears has been found to be about $68: 20: 2: \mathrm{I}$, indicating the existence of a balanced lethal system, with about $\mathrm{I}_{4}$ per cent. of recombination between the two defective factors. 

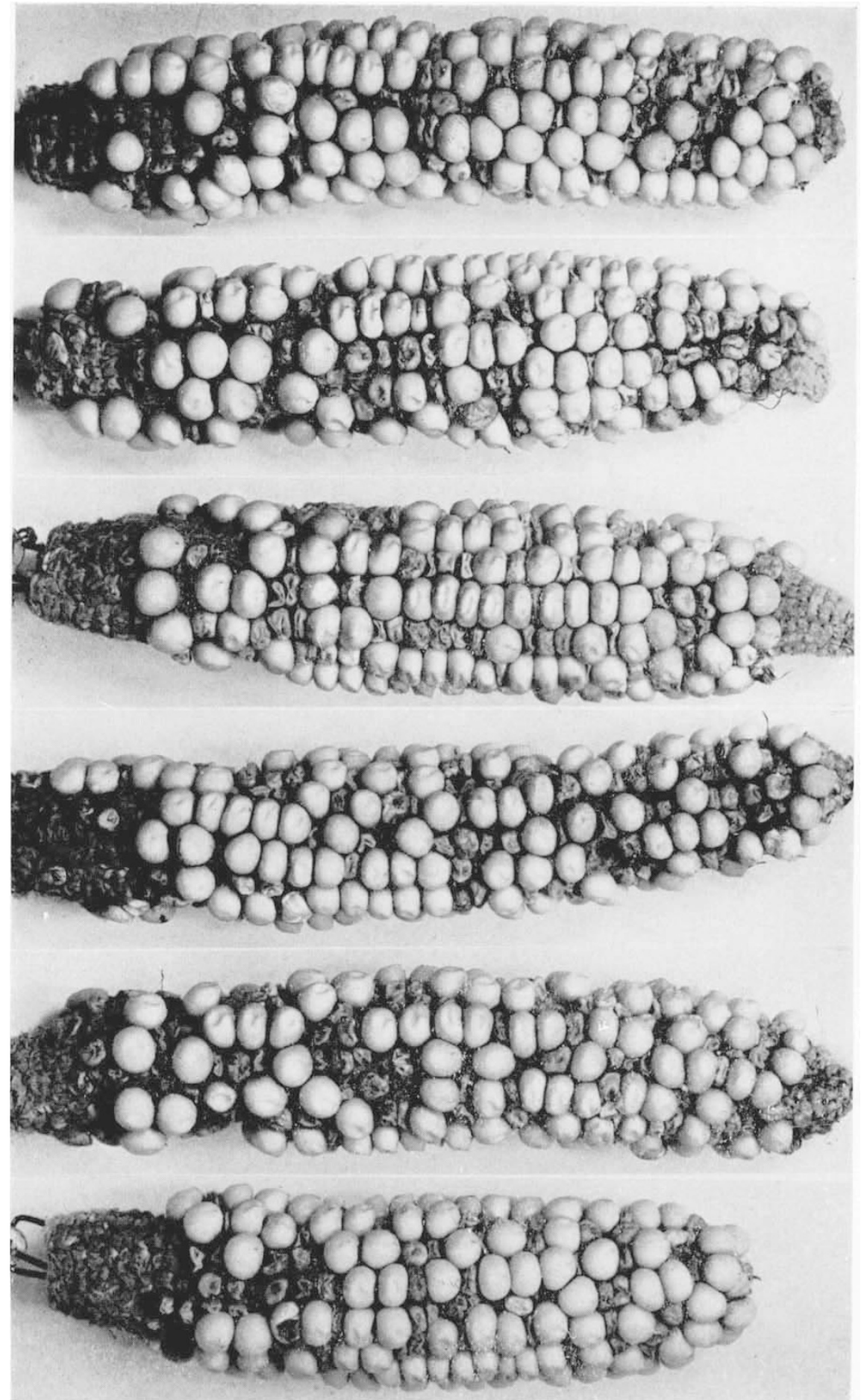
After self-pollination, 94 plants produced sufficient amounts of seeds for progeny tests. Of the remaining, 18 yielded abundant seed when pollinated with pollen of diploid homozygous recessive plants (table 2). One plant (56R55 24 , table 2) did not bear seeds,

TABLE 2

Transmission rates of the $\mathrm{Ws}(\mathrm{pbg})$ locus in the tested and control plants (see figure $\mathrm{I}$, and text) *

\begin{tabular}{|c|c|c|c|c|c|c|c|}
\hline \multirow{2}{*}{$\begin{array}{c}\begin{array}{r}\text { Popula- } \\
\text { tion } \\
\text { Plant } \\
\text { No. }\end{array} \\
\end{array}$} & \multicolumn{7}{|c|}{ Per cent. of non-albino offsprings ( $W s(p b g)$ transmission) } \\
\hline & $5^{6} \mathrm{R}_{55}$ & $5^{6} R_{56}$ & $56 \mathrm{R}_{57}$ & $56 \mathrm{R} 62$ & $56 \mathrm{R} 85$ & $56 \operatorname{Rog} \dagger$ & $56 \mathrm{R}_{1} 6 \dagger$ \\
\hline $\begin{array}{l}1 \\
2 \\
3 \\
4 \\
5 \\
6 \\
7 \\
8 \\
9 \\
10 \\
11 \\
12 \\
13 \\
14 \\
15 \\
16 \\
17 \\
18 \\
19 \\
20 \\
21 \\
22 \\
23 \\
24 \\
25 \\
26\end{array}$ & $\begin{array}{c}54 \cdot 5 \\
25 \cdot 0 \\
33 \cdot 2 \\
48 \cdot 9 \\
8 \cdot 1 \\
18 \cdot 6^{+} \\
11 \cdot 4 \\
39 \cdot 6^{+} \\
60 \cdot 0 \\
23 \cdot 9 \\
42 \cdot 7 \\
42 \cdot 0 \\
17 \cdot 6 \\
21 \cdot 6 \\
17 \cdot 9 \\
22 \cdot 7 \\
20 \cdot 0 \\
21 \cdot 1 \\
22 \cdot 3 \\
24 \cdot 0 \\
19 \cdot 6 \\
48 \cdot 4 \\
21 \cdot 9 \\
60 \cdot 2^{+} \\
44 \cdot 6 \\
\ldots\end{array}$ & $\begin{array}{c}20 \cdot 0 \\
21 \cdot 3 \\
23 \cdot 1 \\
10 \cdot 6^{+} \\
8 \cdot 0^{+} \\
24 \cdot 5 \\
13 \cdot 9 \\
26 \cdot 2 \\
21 \cdot 8 \\
11 \cdot 9^{+} \\
32 \cdot 4 \\
35 \cdot 5 \\
24 \cdot 6 \\
23 \cdot 8 \\
18 \cdot 7 \\
24 \cdot 6 \\
9 \cdot 6 \\
9 \cdot 0^{+} \\
17 \cdot 2 \\
22 \cdot 3 \\
20 \cdot 4 \\
28 \cdot 6 \\
15 \cdot 1 \\
28 \cdot 5^{+} \\
36 \cdot 9 \\
26 \cdot 5\end{array}$ & $\begin{array}{c}20 \cdot 0 \\
\ldots \\
42 \cdot 9 \\
19 \cdot 3^{+} \\
\ldots \\
14 \cdot 9^{+} \\
13 \cdot 2 \\
26 \cdot 9^{+} \\
17 \cdot 5 \\
27 \cdot 5 \\
\ldots \\
\ldots \\
14 \cdot 3 \\
15 \cdot 2 \\
55 \cdot 2 \\
42 \cdot 0 \\
37 \cdot 8 \\
10 \cdot 3 \\
27 \cdot 0 \\
31 \cdot 9 \\
31 \cdot 5 \\
12 \cdot 5 \\
28 \cdot 5 \\
23 \cdot 8+ \\
\ldots \\
\ldots\end{array}$ & $\begin{array}{c}41 \cdot 8 \\
18 \cdot 2 \\
16 \cdot 3 \\
16 \cdot 7 \\
31 \cdot 9 \\
10 \cdot 1 \\
24 \cdot 0 \\
7 \cdot 1^{+} \\
3 \cdot 7 \\
12 \cdot 2 \\
21 \cdot 4 \\
24 \cdot 9 \\
18 \cdot 7 \\
34 \cdot 1^{+} \\
20 \cdot 9 \\
14 \cdot 0 \\
28 \cdot 9 \\
38 \cdot 0 \\
23 \cdot 6 \\
\ldots \\
15 \cdot 2^{+} \\
26 \cdot 5 \\
45 \cdot 1 \\
\ldots \\
11 \cdot 4 \\
9 \cdot 5^{+}\end{array}$ & $\begin{array}{c}47 \cdot 6 \\
\ldots \\
9 \cdot 8 \\
22 \cdot 4 \\
25 \cdot 0^{+} \\
20 \cdot 3^{+} \\
28 \cdot 0 \\
13 \cdot 0 \\
8 \cdot 5 \\
18 \cdot 4 \\
22 \cdot 6+ \\
12 \cdot 7 \\
21 \cdot 7 \\
24 \cdot 8 \\
29 \cdot 2 \\
29 \cdot 4 \\
17 \cdot 9 \\
\ldots \\
\ldots \\
\ldots \\
\ldots \\
16 \cdot 5 \\
13 \cdot 0 \\
\ldots \\
\ldots \\
\ldots\end{array}$ & $\begin{array}{r}11 \cdot 6 \\
15 \cdot 6 \\
10 \cdot 9 \\
18 \cdot 1 \\
22 \cdot 8 \\
10 \cdot 4 \\
11 \cdot 7 \\
9 \cdot 4 \\
15 \cdot 4 \\
18 \cdot 6 \\
18 \cdot 8 \\
10 \cdot 8 \\
16 \cdot 0 \\
9 \cdot 7 \\
12 \cdot 8 \\
17 \cdot 0 \\
8 \cdot 9 \\
10 \cdot 2 \\
14 \cdot 9 \\
18 \cdot 8 \\
20 \cdot 2 \\
14 \cdot 6 \\
22 \cdot 6 \\
24 \cdot 3 \\
\ldots . \\
\ldots\end{array}$ & $\begin{array}{r}6 \cdot 7 \\
15 \cdot 4 \\
1 \ldots \cdot \\
8 \cdot 4 \\
18 \cdot 7 \\
11 \cdot 9 \\
17 \cdot 4 \\
17 \cdot 1 \\
22 \cdot 9 \\
11 \cdot 1 \\
25 \cdot 7 \\
17 \cdot 0 \\
53 \cdot 3 \\
11 \cdot 6 \\
25 \cdot 0 \\
13 \cdot 2 \\
11 \cdot 4 \\
11 \cdot 1 \\
15 \cdot 5 \\
9 \cdot 0 \\
16 \cdot 9 \\
15 \cdot 9 \\
8 \cdot 9 \\
8 \cdot 0 \\
18 \cdot 7 \\
17 \cdot 2\end{array}$ \\
\hline $\begin{array}{c}\text { No. above } 32.5 \\
\text { per cent. } \\
\text { Per cent. no. above } \\
32.5 \text { per cent. }+\end{array}$ & $\begin{array}{l}\text { 10 } \\
9.9\end{array}$ & $1 \cdot 9$ & $\begin{array}{l}4 \\
4 \cdot 8\end{array}$ & $\begin{array}{l}4 \\
3 \cdot 4\end{array}$ & $1 \cdot 1$ & 0 & $\begin{array}{l}\text { I } \\
0.7\end{array}$ \\
\hline
\end{tabular}

* Many of the values in the body of the table are averages of several samples each taken from a different capsule. In some of the progenies the inter-capsule intra-plant variability was much higher than expected. In each progeny over 100 seedlings were germinated. The numbers followed by a + are the results of backcrosses to the diploid homozygous recessives. The rest are products of selfing.

$\dagger$ Diploid control (2n ws ws +1 Ws $(p b g) \times$ self $)$.

¥ Percentages of tested plants, including albino seedlings, that transmitted the $W s(p b g)$ locus to more than 32.5 per cent. of their offspring. These percentages are estimates of the rate of interspecific chromosomal exchanges which have transferred the $W s(p b g)$ locus to a $t b c$ chromosome in the parents of the tested plants.

either on selfing or when pollinated with pollen of diploid $t b c$ plants, but its own pollen proved to be functional when back-crossed to diploid females. Both selfing and back-crossing of the remaining I 7 plants failed to yield functional seeds. 
For control, two samples of selfed mottled diploid heterozygous alien addition plants (2n ws ws $(t b c)+\mathrm{I} W s(p b g))$ were progeny tested (table 2, the two right columns). In fig. 2, the frequency distribution of the "transmission rates" of all the five autotriploid samples are compared with the equivalent distribution of the diploid controls.

Division of the abscissa at the 32.5 per cent. point, produced two classes: (I) Up to 32.5 per cent. transmission of the $W s(p b g)$ locus. Most of the plants that fell into this class presumably carried the $W s(p b g)$ locus on the original unpaired $p b g$ univalent. (ii) Above
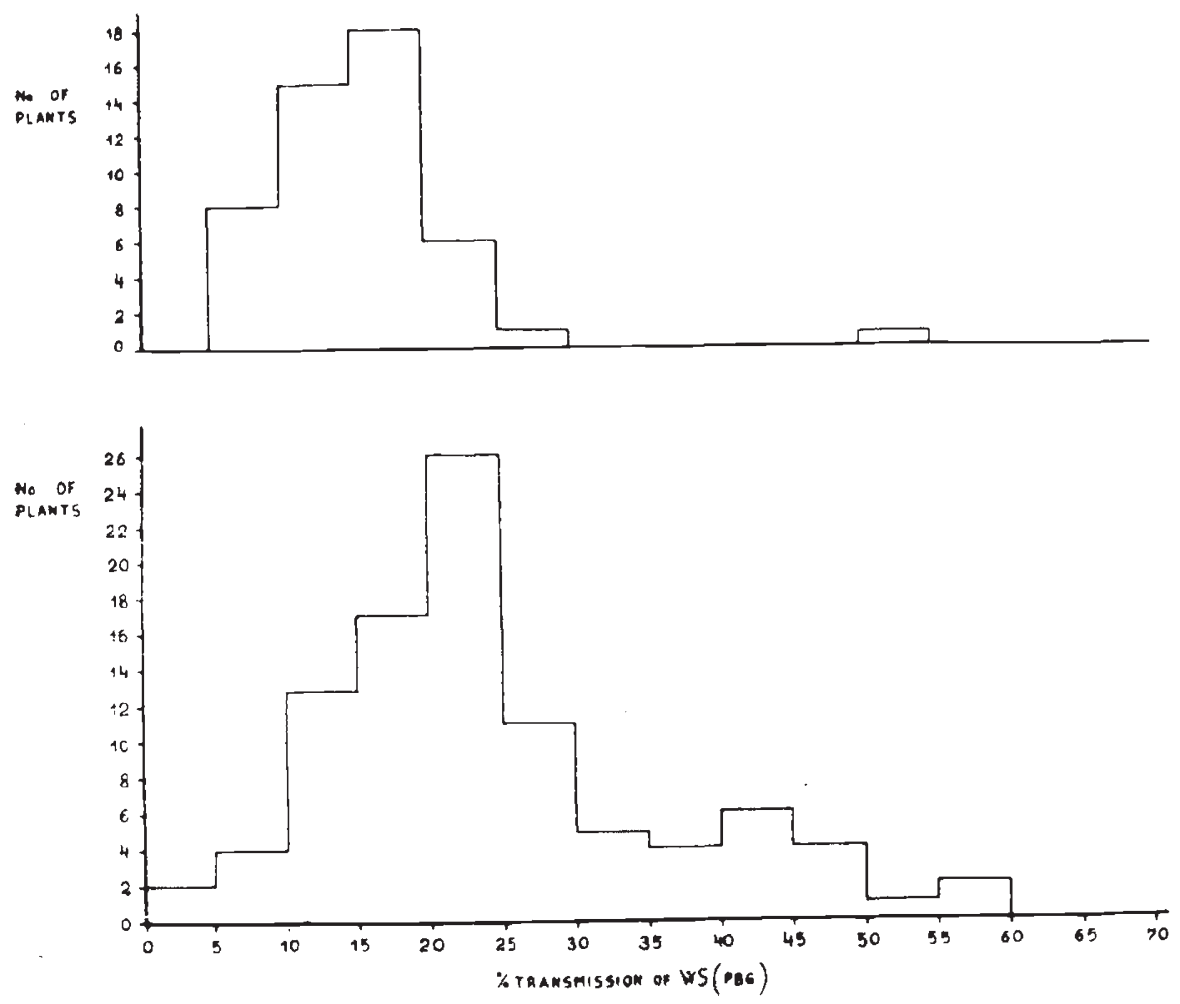

Fig. 2.-Distribution of the transmission rates of table 2.

Upper histogram. Diploid control ( $2 n$ ws ws $+1 W s(p b g) \times$ self), 49 plants.

Lower histogram. Self progeny of Autotriploid $\times$ diploid parents ( $3^{n}$ ws ws ws $+1 W_{s}(p b g$ ) $\times 2 n$ ws ws) 94 plants.

32.5 per cent. transmission. The high transmission of this class is chiefly due to attachment of the $p b g$ segments carrying the $W s(p b g)$ locus, to $t b c$ chromosomes. The interspecific chromosomal exchanges (rare crossing-overs or translocations) which are responsible for the above attachments have taken place (with rare exceptions) during meiosis of the tested alien addition parents of the tested plants. Thus, the proportion of plants which fell into the second class provided estimates for the rate of chromosomal exchanges between the alien $W s(p b g)$ carrying chromosome and the $t b c$ genome. The estimates are given in the bottom line of table 2. 
The choice of 32.5 per cent. for a boundary, probably furnished low estimates for the rate of exchanges. It is most likely, that the majority of $27 \cdot 5-32.5$ per cent. transmission group were also products of chromosomal interchanges of long pbg segments or interchanged chromosomes in a "trisomic" condition, where the interchanged chromosome has two semi-homologous unmodified $t b c$ chromosomes.

The proportion of the "above 32.5 per cent." in all the autotriploid back-cross progenies was higher than that of the two control samples. Similar experiments with the same locus were previously conducted on a large scale at the diploid level (Moav, I958, I 96I). These experiments indicated an interspecific chromosomal exchange frequency of $I$ to $I .5$ per cent. Fitting the observed rates of the autotriploid samples to $\mathrm{r} \cdot 5$ per cent. and using the binomial test, showed a significant difference.

\section{DISCUSSION}

First metaphase meiotic plates of pollen mother cells of $F_{1}$ hybrids between Nicotiana tabacum $(t b c)$ and plumbaginifolia $(p b g)$, show a mode of 3 bivalents (Goodspeed, 1954). The bivalents are held by single chiasmata and are visibly heteromorphic. Since $t b c$ haploids display an average of one bivalent, it may be assumed that the average interspecific meiotic pairing in the $F_{1}$ hybrids is only two bivalents per sporocyte (Cameron and Moav, 1957). Thus, the average bivalent formation for a single $p b g$ chromosome $(n=10)$ should be 0.2 per sporocyte, or one bivalent in five sporocytes. If it is further assumed that the observed bivalents are held by true chiasmata that result in exchange of chromosomal segments, then an average of ro per cent. of the hybrid's spores should carry a pbg marker on exchanged chromosomes. The $F_{1} t b c-p b g$ hybrids are completely sterile but the sesquidiploids $(2 n t b c+n p b g)$ and their back-crosses to $t b c$ are fertile. In the last group the above rate of interspecific chromosomal exchange was actually measured with several loci and was found to be much lower than the expected ro per cent. The $W_{s}(p b g)$ marker was incorporated into a $t b c$ chromosome in around I per cent. of the offspring, and the proportion of other $p b g$ loci which were studied were even lower (Moav, 1958; Moav and Cameron, 1960).

The best explanation for the discrepancy between the expected and observed rates of interspecific chromosomal exchanges seems to be competition for pairing. That is, in sesquidiploids and diploid alien addition derivatives, each $t b c$ chromosome has a completely homologous chromosome to pair with, therefore it would only rarely pair with the alien chromosome with which it shares only minimal homology. A combination of the presumed high frequency of interspecific pairing of the $F_{1}$ hybrids with the fertility of the sesquid ploids or their back-cross derivatives may elevate the actual rate of interspecific gene transfer.

In meiosis of autotriploids, the total length of the unpaired segments 
adds up to a complete unpaired genome, because only two chromosomes may pair at any single point. The unpaired genome is available for pairing without competition if alien chromosomes are present in the nucleus.

The results, reported here show a significant increase in the rate of interspecific chromosomal exchanges on the autotriploid level. Nevertheless, they should be looked upon as indicative only, since the methods employed were rather crude and could not eliminate large variability due to extraneous factors.

\section{SUMMARY}

When there is limited meiotic pairing in interspecific hybrids, the $\mathrm{F}_{1}$ hybrids are sterile. In order to restore fertility, one needs to use a tetraploid recipient and produce triploid hybrids. The triploid hybrids are then backcrossed repeatedly to the recipient diploid species. By a rare interspecific chromosomal exchange, a desirable donor locus is incorporated into the recipient's genome, and the rest of the donor genome is eliminated. The rare occurrence of interspecific chromosomal exchanges in hybrids of distantly related species is one of the limiting factors in artificial transfer of genes between species, and hence it limits the potential gene pool at the disposal of the breeder.

The present paper describes a method that might increase the above rate of transfer in some plant species. The method consists of incorporating the alien chromosomes into an autotriploid recipient nucleus. The hypothesis that autotriploidy is more conducive to interspecific chromosome exchanges is based on the known fact that in meiosis of autotriploids only two chromosomes may pair at any single point. The total length of the unpaired segments adds up to a complete unpaired genome, which is available without competition for pairing and segmental exchange with alien chromosomes.

Experimental results showed a significant increase in the rates of interspecific chromosomal transfer at the triploid level. Nicotiana tabacum was the recipient species, and $\mathcal{N}$. plumbaginifolia the donor, Ws (White-seedlings) being the marker gene.

Acknowledgments.-The current study started under the supervision of the late Professor R. E. Clausen. Thanks are especially due to Dr Ronald R. Cameron for his continuing guidance and advice throughout the research, and the writing of the manuscript, to Dr E. R. Dempster, Dr Ruth Guttman, Dr N. Feinbrun and Dr D. Zohary for their helpful contributions to the improvement of the manuscript, and to Mr Roy Sahara for his valued technical assistance.

\section{REFERENCES}

AR-RUSHDI, ABBAS, H. 1957. The cytogenetics of variegation in a species hybrid in Nicotiana. Genetics, 42, 312.

CAMERON, D. R., AND MOAV, R. 1957. Inheritance in Nicotiana tabacum. XXVII. Pollen killer, an alien genetic locus inducing abortion of microspores not carrying it. Genetics, 42, 326. 
CLAusen, R. E. 1952. The cytogenetics of introgression (Abstract). Science, Ir5, $48 \mathrm{r}$.

goodspeed, T, H, 1954. The genus Nicotiana. Chronica Botanica, Waltham, Mass., U.S.A.

MOAV, R. 1957. Somatic chromosome instability in Nicotiana hybrids. Unpublished Ph.D. thesis, deposited in Univ. of Calif. Lib.

MOAV, R. 1958. Inheritance in Nicotiana tabacum. XXIX. The relationship of residual chromosome homology to interspecific gene transfer. Amer. Nat., XLII, No. 866, 1958.

MOAV, R. 196r. Genetic instability in Nicotiana hybrids. II. A study of the $W s(p b g)$ locus of $\mathcal{N}$. plumbaginifolia in $\mathcal{N}$. tabacum nucleus. Genetics, 46 : 1069-1088.

MOAV, R., AND CAMERON, D. R: 196o. Genetic instability in Nicotiana hybrids. I. The expression of instability in Nicotiana tabacum $\times \mathcal{N}$. plumbaginifolia hybrids. Amer. Journ. Bot., 47, No. 87. 